\title{
Analysis of trihalomethane precursor removal from sub-tropical reservoir waters by a magnetic ion exchange resin using a combined method of chloride concentration variation and surrogate organic molecules
}

Athit Phetrak, Jenyuk Lohwacharin, Satoshi Takizawa

Department of Urban Engineering, Graduate School of Engineering, The University of Tokyo, 7-3-1 Hongo, Bunkyo-ku, Tokyo 113-8656 Japan

Corresponding author: Athit Phetrak

Environmental Engineering Course

Department of Urban Engineering

Graduate School of Engineering

The University of Tokyo

7-3-1 Hongo, Bunkyo-ku

Tokyo 113-8656 Japan

Tel: +813-5841-6248

E-mail:phetrak@env.t.u-tokyo.ac.jp; athit.phetrak@gmail.com 


\begin{abstract}
In small reservoirs in tropical islands in Japan, the disinfection by-product formation potential is high due to elevated concentrations of dissolved organic matter (DOM) and bromide. We employed a combined method of variation of chloride concentrations and the use of DOM surrogates to investigate removal mechanisms of bromide and different fractions of DOM by chloride-based magnetic ion exchange $\left(\mathrm{MIEX}^{\circledR}\right)$ resin. The DOM in reservoir waters was fractionated by resins based on their hydrophobicity, and characterized by size-exclusion chromatography and fluorescence excitation-emission matrix spectrophotometry. The hydrophobic acid (HPO acid) fraction was found to be the largest contributor of the trihalomethane (THM) precursors, while hydrophilic acid (HPI acid) was the most reactive precursors of all the four THM species. Bromide and DOM with a molecular weight (MW) greater than $1 \mathrm{kDa}$, representing HPO acid (MW 1-3 kDa) and HPI acid (MW 1-2 kDa), were effectively removed by MIEX $^{\circledR}$ resin; however, DOM with a MW lower than $1 \mathrm{kDa}$, representing HPI non-acid, was only moderately removed. The removal of THM precursors by MIEX $^{\circledR}$ resin was interfered by high chloride concentrations, which was similar to the removal of glutamic acid (HPI acid surrogate) and bromide. However, elevated chloride concentrations had only a minor effect on tannic acid (HPO acid surrogate) removal, indicating that HPO acid fraction was removed by a combination of ion exchange and physical adsorption on MIEX ${ }^{\circledR}$ resin. Our study demonstrated that the combined use of DOM surrogates and elevated chloride concentrations is an effective method to estimate the removal mechanisms of various DOM fractions by MIEX $^{\circledR}$ resin.
\end{abstract}

Keywords: Adsorption; Dissolved organic matter; Drinking water treatment; Ion exchange; Trihalomethane precursor removal. 


\section{1.\# INTRODUCTION}

Dissolved organic matter (DOM) is present in all drinking water sources and is a complex mixture of heterogeneous compounds derived from the decomposition of plant and animal tissue, including humic compounds, amino acids, proteins and carbohydrates. (Thurman, 1985; Norwood et al. 1987; Sellner and Nealley, 1997; Wang et al. 2009). Characteristics and concentrations of DOM in natural waters vary depending on climate, geology, topography, and other environmental factors (Fabris et al. 2008; Sharp et al. 2005). Generally, most of the compounds comprising DOM have anionic character as a result of the structure-bound carboxylic and phenolic groups such as humic and fulvic acids (Kim and Yu, 2005), whilst the rest of the DOM consist of neutral compounds, such as polysaccharides and proteins (Leenheer and Croué, 2003). However, DOM in natural waters is often characterized by isolation DOM fractions, such as hydrophobic (HPO), hydrophilic (HPI), and molecular weights (MW), and/or their functionalities.

DOM and bromide are considered as the precursors of disinfection by-products (DBPs), such as trihalomethanes (THMs), produced in the chlorination process (Richardson et al. 1999; Hsu and Singer, 2010). In Japan, drinking water sources in sub-tropical islands contains high DOM concentration of 2.5-7.8 $\mathrm{mg}-\mathrm{C} / \mathrm{L}$, while high bromide and chloride concentrations were found in the range of $0.20-0.59 \mathrm{mg} / \mathrm{L}$ and $87-205 \mathrm{mg} / \mathrm{L}$, respectively (Tochimoto et al. 2010). Although coagulation-flocculation and adsorption by activated carbon have been extensively applied in treatment processes, the treated water still contains high concentrations of THM precursors, particularly bromide because these processes could not effectively remove bromide (Kristiana et al. 2011; Xu et al. 2013). Thus, additional processes, such as anion exchange resin (AER) processes, are required to minimize the THM precursors (Hsu and Singer, 2010). Typically, the AER process using magnetic ion exchange $\left(\right.$ MIEX $^{\circledR}$ ) resin has been employed as pretreatment (Drikas et al. 2011) of a coagulation-flocculation process in water treatment plants for the removal of DOM and bromide to reduce DBP formation (Gan et al. 2013; Phetrak et al. 2014). In a water treatment plant in Ogasawara Islands, located in the sub-tropical region in Japan, the MIEX ${ }^{\circledR}$ process was installed after coagulation-flocculation and sedimentation processes to prolong the operational life time of MIEX $^{\circledR}$ resin. However, the second water treatment plant is now being designed employing the MIEX $^{\circledR}$ process as a pretreatment for the coagulation-flocculation process.

Hsu and Singer (2010) found that chloride concentration is an important factor in inhibiting bromide removal by AER. Ion exchange was reported to be the main mechanism of 
charged DOM removal by AER in absence of chloride or at low chloride concentration (Boyer and Singer, 2008; Bond et al. 2010). A high $\mathrm{NaCl}$ concentration, i.e. $0.8 \mathrm{~mol} / \mathrm{L}$, influenced tannic acid adsorption by surfactant-modified zeolites, which was estimated to be cause by a combination of electrostatic attraction and the other interactions such as hydrogen bonding and organic partitioning (Lin et al 2011). Nonetheless, these studies had not elaborated the influence of various chloride concentrations on the removal of DOM fractions by MIEX $^{\circledR}$ resin.

To investigate physical adsorption of DOM by AERs, DOM removal by ion exchange can be minimized by decreasing the $\mathrm{pH}$ to a value where the negative charge on the DOM is negligible. Croué et al (1999) observed adsorption of different DOM fractions (HPO and HPI) present in natural water by AERs at different $\mathrm{pH}(\mathrm{pH} 4-10)$ and found that the effectiveness of DOM removal by AERs can be strongly influenced by $\mathrm{pH}$. At basic $\mathrm{pH}(\mathrm{pH}$ 10), where the negative charge of the DOM is strong, ion exchange mechanism was, whereas physical adsorption was dominant for DOM removal in acidic condition ( $\mathrm{pH} 4)$. However, varying $\mathrm{pH}$ may not be appropriate to identify the DOM removal mechanisms by AERs possibly due to the transformation of DOM structures (Oćwieja et al. 2015). Therefore, varying chloride concentration could be potentially an effective approach to investigate DOM removal mechanism by AER because it does not alter the structure of adsorbent and/or adsorbate (Lin et al. 2011). However, to the best of our knowledge, there is only limited number of studies that had reported the interaction between DOM fractions and AER or between bromide and AER by varying chloride concentrations in aquatic solution.

Therefore, this study aimed to elucidate the removal mechanisms of DOM fractions by chloride-based MIEX $^{\circledR}$ resin using a combination of DOM surrogate compounds representing each DOM fraction in natural water and variation of chloride concentration. The competitive effect of chloride on bromide removal by MIEX $^{\circledR}$ resin was also investigated. Furthermore, the effect of DOM characteristics on THM formation was investigated by the resin fractionation method (DAX-8 and XAD-4). Simultaneous removal of DOM and bromide by MIEX $^{\circledR}$ resin for THM formation potential (THMFP) reduction was also investigated in this study.

\section{2.\# MATERIALS AND METHODS}

\section{1\#Sampling site and water collection}

Water sampling was conducted in the sub-tropical islands of Ogasawara, Japan in September 2012. Water samples were collected from three reservoirs in Chichijima Island 
$\left(\mathrm{E} 142^{\circ} 11^{\prime} \mathrm{N} 27^{\circ} 05^{\prime}\right.$, land area $23.8 \mathrm{~km}^{2}$ ), namely $\mathrm{CH} 1, \mathrm{CH} 2$ and $\mathrm{CH} 3$. Another sample (HA) was obtained from a reservoir in Hahajima Island (E142 ${ }^{\circ} 10^{\prime} \mathrm{N} 26^{\circ} 38^{\prime}$, land area $20.2 \mathrm{~km}^{2}$ ) (Fig. 1). The water samples were packed in an icebox and transferred to the laboratory at the University of Tokyo. The samples were then pre-filtered through $0.45 \mu \mathrm{m}$ hydrophilic PTFE membrane filters (Millipore, JHWP09025), hereafter referred to as raw waters, and stored in the dark at $4^{\circ} \mathrm{C}$ until use.
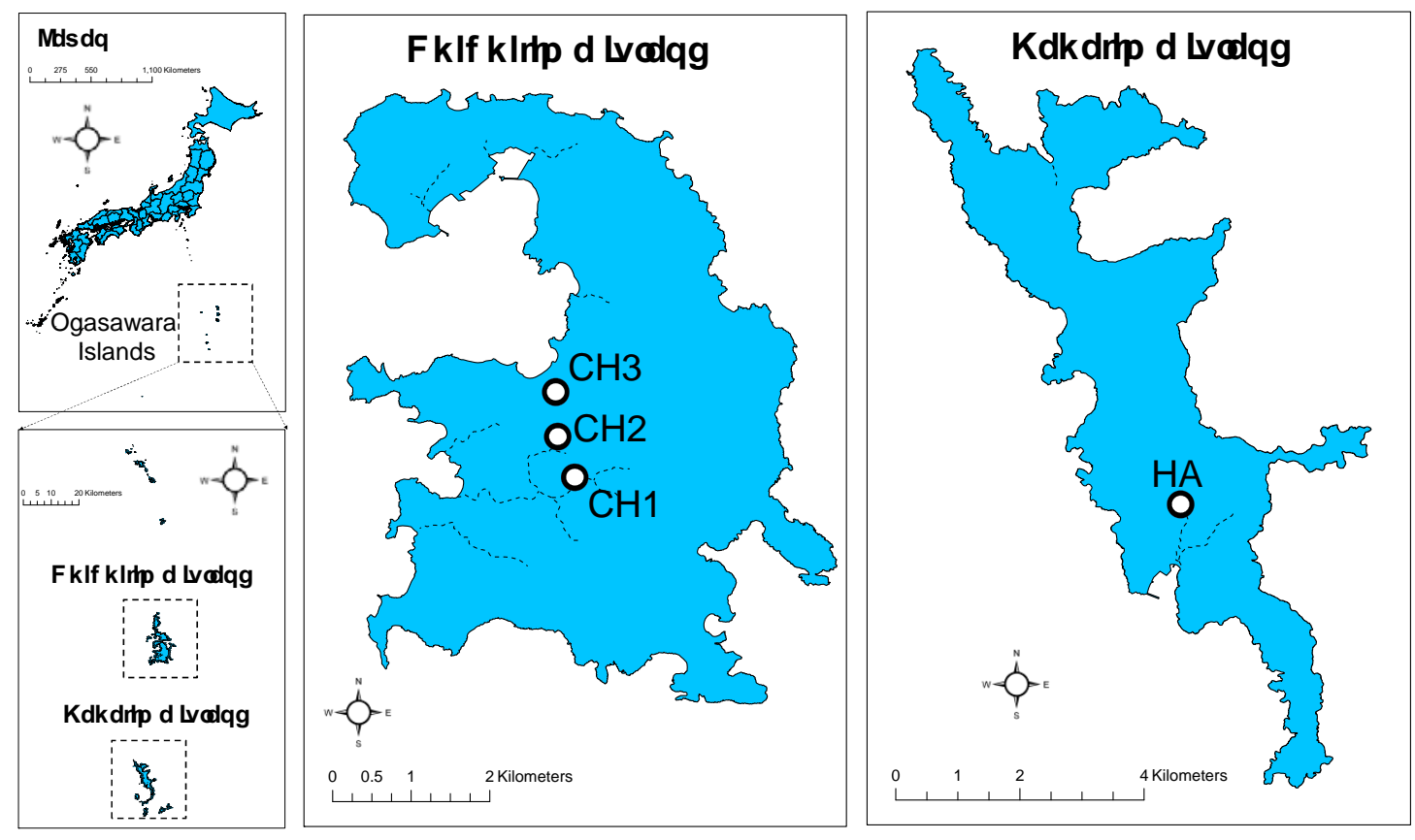

Fig. 1. Sampling location in the Ogasawara Islands.

\section{2\#DOM fractionation by resins (DAX-8 and XAD-4)}

DOM in the raw water was fractionated using a two-column array of Supelite DAX-8 and Amberlite XAD-4 (SUPELCO, Supelco Park, Bellefonte, PA, USA), which separated DOM into three fractions, i.e., HPO acid (DAX-8 adsorbable), HPI acid (XAD-4 adsorbable), and HPI non-acid (neither DAX-8 nor XAD-4 adsorbable). Briefly, $750 \mathrm{~mL}$ of raw water was acidified with $10 \mathrm{~N} \mathrm{HCl}$ to $\mathrm{pH}$ 2. The acidified water was passed through column arrays of DAX-8 and XAD-4 to fractionate the DOM, following the same procedure employed by Lohwacharin et al. (2010). The HPI non-acid fraction was collected in the effluent from both DAX-8 and XAD-4 columns. The HPO acid and HPI acid fractions were removed from the DAX-8 and XAD-4 columns by rinsing with $0.1 \mathrm{~N} \mathrm{NaOH}$, respectively. After fractionation, each DOM fraction was adjusted to neutral $\mathrm{pH}$. 


\section{3\#Batch adsorption experiment}

Batch adsorption experiments were conducted using a commercially available strong base AER in a bottle-point method to investigate DOM and bromide removal from raw waters and synthetic waters. The MIEX $^{\circledR}$ resin is a polyacrylic macroporous resin with magnetized iron oxide incorporated into the structure. MIEX $^{\circledR}$ resin had the highest DOM removal rate among various AERs in our previous study (Phetrak et al., 2014), and was used in chloride form in this study. The characteristics of the MIEX $^{\circledR}$ resin are shown in Table S1 (supporting information). The adsorption experiments by the MIEX $^{\circledR}$ resin were performed by adding $4.8 \mathrm{~g}$ of the $\mathrm{MIEX}^{\circledR}$ resin into a 1-L flask containing $600 \mathrm{~mL}$ raw water, corresponding to an $\mathrm{MIEX}^{\circledR}$ resin dosage of $8 \mathrm{~g} / \mathrm{L}$ (equivalent to $9.5 \mathrm{~mL} / \mathrm{L}$ based on the packing density shown in Table S1). The weight of MIEX $^{\circledR}$ resin was measured on the wet-weight basis following the method reported by Boyer and Singer (2008). Adsorption experiments were conducted at $25^{\circ} \mathrm{C}$ by horizontally shaking the flasks at $200 \mathrm{rpm}$ for $30 \mathrm{~min}$, following Xu et al. (2013). The MIEX $^{\circledR}$-treated waters were filtered through pre-rinsed 0.45 $\mu \mathrm{m}$ PTFE filters ( $\mathrm{JH}$, Millipore) before DOM and anion analyses and measurements of THMFP by chlorination.

Separately from the fractionation of DOM in the natural water samples, synthesis of water samples with surrogate DOM compounds representing the major fractions of DOM were used to analyze the chemical and physical properties affecting adsorbability to the MIEX $^{\circledR}$ resin, thus enabling elucidation of the removal mechanisms of DOM fraction removals by the $\mathrm{MIEX}^{\circledR}$ resin. Adsorption experiments were conducted with synthetic waters containing one of the four surrogate DOM compounds with bromide and varying chloride concentrations to investigate the effect of chloride on the simultaneous removal of DOM and bromide by the MIEX $^{\circledR}$ resin. The four surrogate DOM compounds included in this study (Table S2) were tannic acid (HPO acid surrogate), glutamic acid (HPI acid surrogate), resorcinol (HPO neutral surrogate) and serine (HPI neutral surrogate) (Wako Pure Chemical Industries Ltd., Japan). Their MWs varied between $1701 \mathrm{~g} / \mathrm{mol}$ and $105 \mathrm{~g} / \mathrm{mol}$ and they had different chemical structures, such as aromatic, aliphatic, carboxylic, and amino acid functional groups. Typically, about 50\% of DOM in surface water is humic substances which can include resorcinol structures (Norwood et al. 1987). High concentration of amino acids (including glutamic acid and serine) can be detected following the occurrence of algal bloom in surface waters (Sellner and Nealley, 1997), while typically their concentrations present in the range of $0.05-1.00 \mathrm{mg} / \mathrm{L}$, constituting $2 \%-3 \%$ of total dissolved organic carbon (DOC) in river water (Thurman, 1985). It was thus anticipated that these surrogate DOM compounds 
could be representative of DOM fractions in surface water and residual organic compounds after post-coagulation. To prepare the synthetic waters, each surrogate DOM compound was dissolved into separate batches of Milli-Q water to a final DOC concentration of $6.3 \pm 0.6$ mg-C/L (mean \pm std. dev.). Each solution was mixed with bromide and chloride stock solutions (335 mg-Br/L KBr, Chameleon reagent, Japan; 21,000 mg/L as sodium chloride, Wako Pure Chemical Industries Ltd., Japan) to achieve an initial bromide concentration of $0.50 \mathrm{mg} / \mathrm{L}$ with various chloride concentrations $(<2.6 \mathrm{mg} / \mathrm{L}, 36 \mathrm{mg} / \mathrm{L}$, and $71 \mathrm{mg} / \mathrm{L})$ at the initial $\mathrm{pH}$ of $6-8$ being adjusted with $\mathrm{NaOH}(0.1 \mathrm{~N}$ and $1 \mathrm{~N})$ or $\mathrm{HCl}(0.1 \mathrm{~N}$ and $1 \mathrm{~N})$. To set at the same MIEX $^{\circledR}$ resin dosage as that used for the raw water $(8 \mathrm{~g} / \mathrm{L}), 0.48 \mathrm{~g}$ of the MIEX $^{\circledR}$ resin was added to $60 \mathrm{~mL}$ of the synthetic water in $100 \mathrm{~mL}$ flasks. To investigate DOM adsorption kinetics, mixed liquor samples were taken at various contact times ranging from 0 to $120 \mathrm{~min}$. For these samples, an aliquot of water was filtered through a pre-rinsed $0.45 \mu \mathrm{m}$ filter (Dismic 45HP, Advantec, Japan) to remove MIEX ${ }^{\circledR}$ resin prior to DOC and anion analyses.

\section{4\#Analytical methods}

The DOC and UV absorbance at $254 \mathrm{~nm}\left(\mathrm{UV}_{254}\right)$ were measured using a total organic carbon (TOC) analyzer (TOC-L, Shimadzu, Japan) and a UV/Vis spectrophotometer (UV-2000, Hitachi, Japan), respectively. The specific UV absorbance at $254 \mathrm{~nm}\left(\mathrm{SUVA}_{254}\right)$, defined as $\mathrm{UV}_{254} / \mathrm{DOC}$, represents the aromaticity of the DOM present in natural water. The apparent molecular weight (AMW) distribution was measured by the high-performance size-exclusion chromatography (HPSEC) with a $\mathrm{UV}_{254}$ detector (Shimadzu Corp., Japan), and the MW of DOM was estimated from the retention times of the polystyrene sulfonate salt standards. It should be noted that the HPSEC analysis using a $\mathrm{UV}_{254}$ detector can examine the AMW of aromatic organic compounds, while some non-aromatic organic compounds may remain undetected. Fluorescence excitation-emission matrix (F-EEM) profiles were measured by a fluorescence spectrophotometer (F-4500, Hitachi, Japan), as described in our previous study (Phetrak et al. 2014).

Anion concentrations were analyzed with an ion chromatography analyzer (Metrohm 861 , Metrohm, Switzerland) with detection limits of $0.020 \mathrm{mg} / \mathrm{L}$ for chloride, $0.010 \mathrm{mg} / \mathrm{L}$ for bromide and $0.015 \mathrm{mg} / \mathrm{L}$ for nitrate. The experiments to determine the THMFP of the water samples were performed as described in our previous study (Phetrak et al. 2014). Briefly, chlorination of the sample waters was performed by adding sodium hypochlorite into samples buffered at $\mathrm{pH} 7.0 \pm 0.2$, followed by $24 \mathrm{~h}$ incubation in the dark at $20^{\circ} \mathrm{C}$ (Japan Water Works 
Association, 2001). The residual free chlorine was maintained at 1-2 mg/L. The reactions were immediately quenched with sodium ascorbate prior to the analysis of THMs. In the literature, various incubation periods of chlorination, such as $24 \mathrm{~h}$ (1 day) (Ates et al. 2007; Bond et al. 2010; Chu et al. 2015; Imai et al. 2003), 2 days (Hua and Reckhow, 2007; Kim and Yu, 2005), 3 days (Liu et al. 2012) and 7 days (Chiang et al. 2009; Gough et al. 2014), were used by the different researchers to fulfill their research objectives. In this study, the incubation period of $24 \mathrm{~h}$ for chlorination represented the hydraulic retention time in the distribution networks in Japan. However, due to the short incubation period, it might be less than the maximum THM formation potential as estimated by the 7-day incubation period in the US EPA method and in the Standard Methods. The THM concentrations of raw water and MIEX $^{\circledR}$-treated water were determined by headspace technique combined with gas chromatograph (GC) - mass spectrometry (GC-MS) according to Phetrak et al. (2014), while the concentrations of THM from different DOM fractions of raw water were determined using a headspace technique by GC (Shimadzu GC-2010 Plus, Japan) with an electron capture detector (ECD) due to the non-availability of the GC-MS instrument. The headspace GC-ECD was operated at an equilibrium temperature of $45^{\circ} \mathrm{C}$ with an injection volume of $250 \mu \mathrm{L}$. The chromatographic column was a J\&W Scientific DB-624 (ø0.53 mm x $30 \mathrm{~m}$ x 3 $\mu \mathrm{m})$. The detector temperature was $240^{\circ} \mathrm{C}$ with a carrier nitrogen gas velocity of $35 \mathrm{~mL} / \mathrm{min}$.

\section{RESULTS AND DISCUSSION}

\subsection{Source water characteristics}

The raw water quality is shown in Table 1 . The four samples had similar water quality characteristics that typically represent sub-tropical reservoir waters, namely, high concentrations of DOC (4.75-7.53 $\mathrm{mg} / \mathrm{L})$, bromide $(0.206-0.262 \mathrm{mg} / \mathrm{L})$ and chloride

$(64.35-75.12 \mathrm{mg} / \mathrm{L})$, as well as high $\mathrm{UV}_{254}$ absorbance $\left(0.150-0.262 \mathrm{~cm}^{-1}\right)$, but lower concentrations of nitrate and sulfate than those found in the typical surface water of the mainland in Japan (Lohwacharin et al. 2010; Lohwacharin and Takizawa 2009; Phetrak et al. 2014; Phetrak et al. 2012).

Table 1. Raw water quality characteristics for the study.

\begin{tabular}{lllll}
\hline Parameter & $\mathrm{CH} 1$ & $\mathrm{CH} 2$ & $\mathrm{CH} 3$ & $\mathrm{HA}$ \\
\hline $\mathrm{pH}$ & 7.96 & 7.69 & 7.53 & 7.60 \\
$\mathrm{DOC}(\mathrm{mg} / \mathrm{L})$ & $7.12 \pm 0.21$ & $7.53 \pm 0.41$ & $6.22 \pm 0.45$ & $4.75 \pm 0.28$ \\
\hline
\end{tabular}




\begin{tabular}{lllll}
\hline $\mathrm{UV}_{254}\left(\mathrm{~cm}^{-1}\right)$ & 0.243 & 0.262 & 0.230 & 0.150 \\
$\mathrm{SUVA}_{254}(\mathrm{~L} / \mathrm{m} . \mathrm{mg})$ & 3.41 & 3.48 & 3.70 & 3.16 \\
Bromide $(\mathrm{mg} / \mathrm{L})$ & 0.244 & 0.229 & 0.262 & 0.206 \\
Chloride $(\mathrm{mg} / \mathrm{L})$ & 65.74 & 64.35 & 75.12 & 65.58 \\
Nitrate $(\mathrm{mg} / \mathrm{L})$ & 0.076 & 0.039 & 0.068 & 0.158 \\
Sulfate $(\mathrm{mg} / \mathrm{L})$ & 9.07 & 9.26 & 10.02 & 10.10 \\
Bromide/chloride ratio & 0.0037 & 0.0036 & 0.0035 & 0.0031 \\
\hline
\end{tabular}

Because there is no human activity in the watershed of these reservoirs, the nitrate concentration was low $(0.039-0.158 \mathrm{mg} / \mathrm{L})$. The high bromide concentration in the raw waters is likely derived from sea water, as evidenced by the similar bromide to chloride ratios $(\mathrm{Br} / \mathrm{Cl})$ between the raw waters $(\mathrm{Br} / \mathrm{Cl}=0.0031-0.0037)$ and that of sea water $(\mathrm{Br} / \mathrm{Cl}=$ 0.0034-0.0036) (Magazinovic et al. 2004). The high SUVA 254 values (3.16-3.70 L/m.mg) of the raw waters indicate the dominance of aromatic DOM compounds, which are mainly derived from the degradation of terrestrial materials (Rautio et al. 2011; Tochimoto et al. 2010). This result was confirmed by the fluorescence index (FI) of the F-EEM results. The FI $\left(f_{450} / f_{500}\right.$, the ratio of fluorescence intensities of emission $(\mathrm{Em})$ at $450 \mathrm{~nm}$ to that at Em 500 $\mathrm{nm}$ with excitation (Ex) at $370 \mathrm{~nm}$ ) was calculated as proposed by McKnight et al. (2001), who reported that a higher FI (1.7 to 2.0) reflects organic matter of an autochthonous (microbial) origin, while values of FI that are 1.4 or less correspond to DOM of an allochthonous (terrestrial) origin (McKnight et al. 2001). Chu et al. (2010) reported that the DOM in water taken from the Qingcaosha reservoir, which is located in the Chongming Island near the estuary of the Yangtze River, was predominantly hydrophobic. They fractionated DOM into six fractions, and four DOM fractions had low FI values between 0.61 and 1.35 , which they estimated to be allochthonous (terrestrial origin), whereas two other fractions containing soluble microbial product (SMP)-like compounds and aromatic proteins had higher FI vales of 2.23 and 2.60, indicating mixing of autochthonous DOM. It was found that the FI of the raw water ranged from 1.38 to 1.43 , which confirmed the predominance of terrestrially derived DOM. These raw water qualities were similar to those of Tai-hu Lake, a drinking water resource on Kinmen Island (Taiwan), showing a similar range of DOC (4.6-8.3 mg/L), UV $254\left(0.117-0.197 \mathrm{~cm}^{-1}\right)$, SUVA $_{254}(1.53-3.63 \mathrm{~L} / \mathrm{m} . \mathrm{mg})$, and bromide concentration (0.042-0.397 mg/L) (Yang et al. 2010).

A comparison of water quality was also made between water resources on the sub-tropical islands and on the mainland in Japan (Phetrak et al. 2014; Yang et al. 2012). The 
river water on the mainland had lower values of DOC (1.75-2.71 mg/L), UV $\mathrm{UV}_{254}(0.043-0.062$ $\mathrm{cm}^{-1}$ ), SUVA $254(2.28-2.44 \mathrm{~L} / \mathrm{m} . \mathrm{mg}$ ) and bromide (up to $0.125 \mathrm{mg} / \mathrm{L}$ ) than those of the sub-tropical islands (Table 1). The difference between these water qualities could be caused by a difference in the DOM origins. Generally, drinking water sources on the mainland in Japan receive wastewater effluents containing mainly the HPI fraction with low $\mathrm{SUVA}_{254}$ values and a low bromide concentration (Imai et al. 2002; Phetrak et al. 2014; Yang et al. 2012). In contrast, reservoir waters in the sub-tropical islands used for drinking water sources had a higher bromide concentration and a higher proportion of the HPO fraction with higher $\mathrm{SUVA}_{254}$ values, which may have resulted from atmospheric deposition of seawater aerosols and droplets and the predominance of terrestrially derived organic materials, respectively. These results indicate that the water quality in sub-tropical islands has unique characteristics, containing a high bromide concentration and HPO acid, which may increase the formation of THM after chlorination.

\subsection{DOM characteristics of raw water}

Figure 2 shows the DOM fractions of raw water samples by resin fractionation. The overall carbon mass recovery for all of the fractions ranged from $91 \%$ to $103 \%$ for the raw water. The results revealed that the raw waters sampled in the four reservoirs in the Ogasawara Islands had similar DOM compositions. The HPO acid fraction was the most dominant fraction of DOM in the raw waters, comprising approximately $75 \%$ of DOM. This result was in agreement with the literature (Chiang et al. 2009; Fabris et al. 2008; Tubić et al. 2013; Wang et al. 2009). In contrast to the HPO acid fraction, the raw waters contained smaller fractions of HPI acid (14\%-19\%) and HPI non-acid (6\%-11\%). Generally, the HPO acid fraction consists of aromatic organic matter, such as humic acid, with a high content of conjugated double bonds and charge density (Sharp et al. 2005), which is in agreement with the high $\mathrm{SUVA}_{254}$ values found for the raw waters in this study. However, other researchers (Lamsal et al. 2012; Lohwacharin and Takizawa, 2009; Xu et al. 2007) reported that the HPI fraction was the dominant DOM fraction in some surface waters. The different proportion of DOM fractions could be due to the difference in the DOM origins, catchment geochemistry, rainfall and other factors. These different results provide more evidence that the results of DOM fractionation cannot be generalized across different localities. 

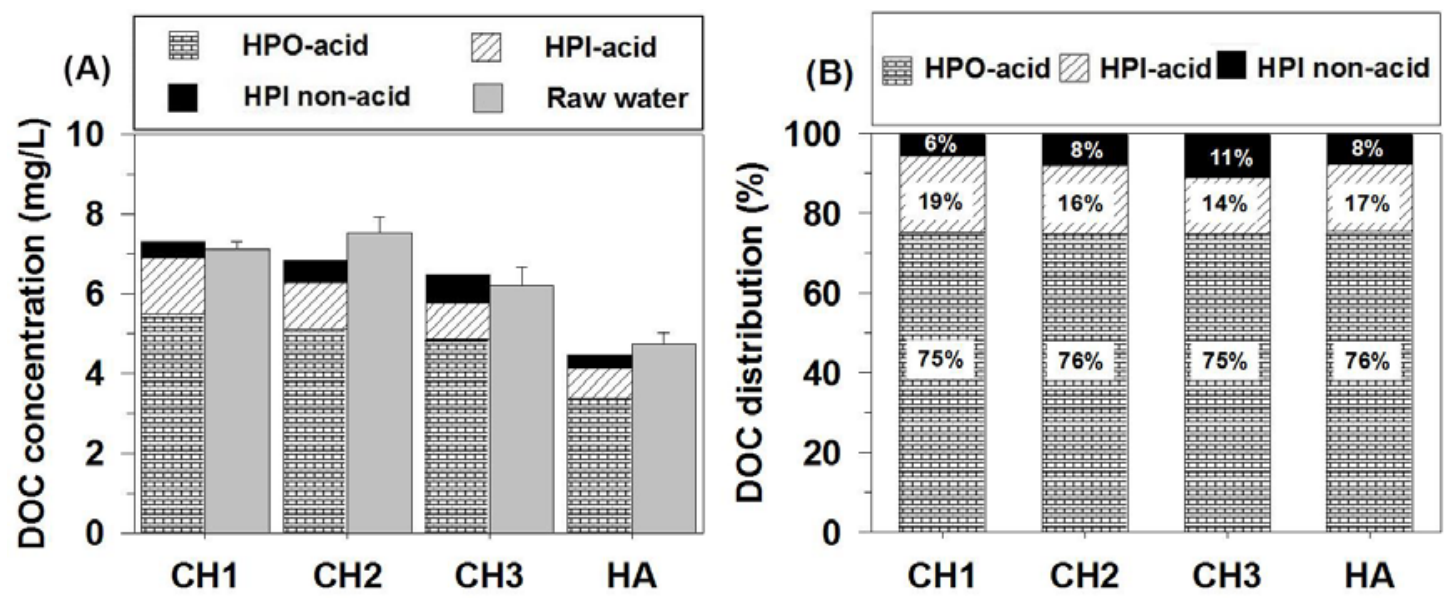

Fig. 2. (A) DOC concentration of DOM fractions by resin fraction from raw water, (B) DOC distribution of DOM fractions from raw waters. Error bars are drawn as the standard deviation from triplicate measurements.

The AMW distribution of the raw waters ( $\mathrm{CH} 2$ and $\mathrm{HA})$ and fractionated DOM by resin fractionation are presented in Fig. S1. The HPO acid had the highest AMW (1-3 kDa) and the highest intensity of $\mathrm{UV}_{254}$ response due to aromatic structures, whereas the HPI non-acid showed the lowest intensity of $\mathrm{UV}_{254}$ response with an AMW of $<1 \mathrm{kDa}$. The HPI acid had an AMW between $1 \mathrm{kDa}$ and $2 \mathrm{kDa}$, which was smaller than the HPO acid fraction but greater than the HPI non-acid fraction.

The SUVA $_{254}$ values reported in our study (Table 1) were in the same range as the high SUVA 254 reported from surface waters by other researchers (Fabris et al. 2008; Gough et al. 2014; Hussain et al. 2013; Kaplan Bekaroglu et al. 2010), possibly due to the similar catchments of the predominant terrestrial sources. However, we found that a majority of aromatic DOM in these sub-tropical islands had a relatively smaller AMW of $4 \mathrm{kDa}$ than the AWM of $10 \mathrm{kDa}$ in the drinking water sources in Norway (Fabris et al. 2008). This result is possibly due to the effect of photodegradation (Wang et al. 2009) and a higher rate of decomposition and solubilization of DOM by microbial communities (Freeman et al. 2001) in the raw waters under sub-tropical climate conditions.

\section{3\#OM and bromide removal by the $\mathrm{MIEX}^{\circledR}$ resin}

\subsubsection{Influence of chloride concentration on simultaneous removal of DOM and bromide}

Simultaneous DOM and bromide removal from raw waters by the MIEX $^{\circledR}$ resin was investigated to minimize THM formation by subsequent chlorination. Table 2 shows that the 
DOC removal rates by the MIEX $^{\circledR}$ resin varied between $81 \%$ and $87 \%$, whereas the removal rates of $\mathrm{UV}_{254}$ absorbing compounds were between $91 \%$ and $95 \%$. The removal rates of $\mathrm{UV}_{254}$ absorbing compounds was higher than the DOC removal rates because of a higher affinity of the MIEX $^{\circledR}$ resin for aromatic DOM (Phetrak et al. 2014; Xu et al. 2013).

Table 2. Water quality after the $\mathrm{MIEX}^{\circledR}$ treatment $\left(\mathrm{MIEX}^{\circledR}\right.$ resin dose of $8 \mathrm{~g} / \mathrm{L}$, contact time of $30 \mathrm{~min})$.

\begin{tabular}{lllll}
\hline Parameter & CH1 & CH2 & CH3 & HA \\
\hline DOC $(\mathrm{mg} / \mathrm{L})$ & $0.91(87 \%)$ & $0.98(87 \%)$ & $1.03(83 \%)$ & $0.92(81 \%)$ \\
$\mathrm{UV}_{254}\left(\mathrm{~cm}^{-1}\right)$ & $0.020(92 \%)$ & $0.013(95 \%)$ & $0.021(91 \%)$ & $0.010(93 \%)$ \\
SUVA $_{254}(\mathrm{~L} / \mathrm{m} . \mathrm{mg})$ & $2.20(36 \%)$ & $1.33(62 \%)$ & $2.04(45 \%)$ & $1.09(66 \%)$ \\
bromide (mg/L) & $0.020(92 \%)$ & $0.024(89 \%)$ & $0.028(89 \%)$ & $0.020(90 \%)$ \\
\hline
\end{tabular}

Note: The percentages of removal rates are given in the parentheses.

Figs. 3A to $3 \mathrm{C}$ show the ion exchange kinetics of the surrogate DOM at different chloride concentrations $(<2.6 \mathrm{mg} / \mathrm{L}-71 \mathrm{mg} / \mathrm{L}$ as min-max concentrations). In the neutral $\mathrm{pH}$ range ( $\mathrm{pH}$ 6-8), tannic acid (HPO acid surrogate) and glutamic acid (HPI acid surrogate) exist predominantly in negatively charged forms, whereas resorcinol (HPO neutral surrogate) and serine (HPI neutral surrogate) are in a net neutral charge form, as indicated by their higher acid dissociation constants (pKa) (Table S2). The charged DOM (i.e., tannic and glutamic acids) were removed considerably by the MIEX $^{\circledR}$ resin, nearly reaching equilibria in 5 min, but resorcinol and serine were not removed by the MIEX $^{\circledR}$ resin within 120 min. However, tannic acid (HPO acid) showed a higher DOC reduction than glutamic acid (HPI acid) at all of the chloride concentrations. 

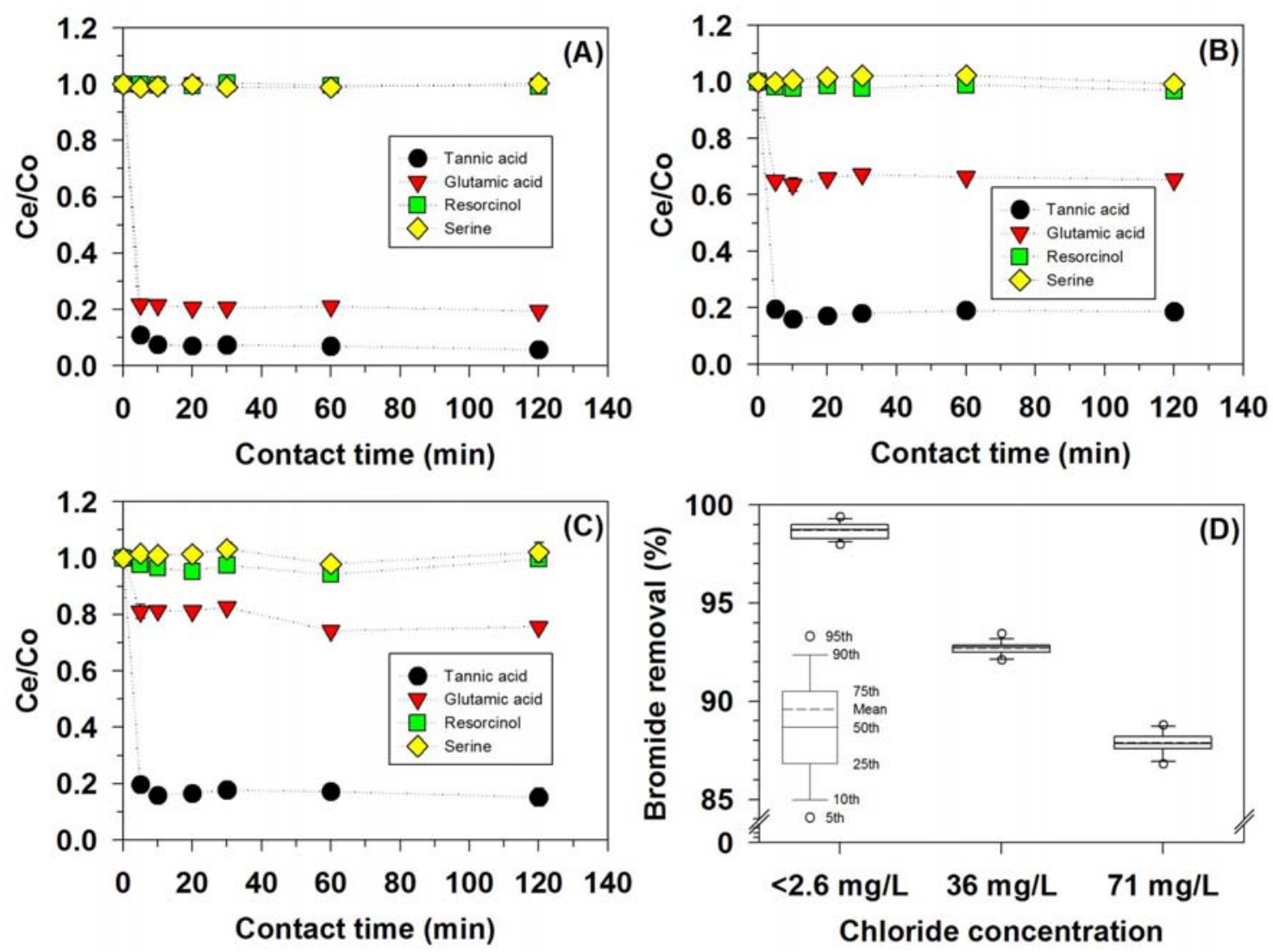

Fig. 3. Effect of chloride concentrations on DOC and bromide removal by $\mathrm{MIEX}^{\circledR}$ at different contact times. The DOC concentration $\left(C_{e}\right)$ of $\mathrm{MIEX}^{\circledR}$-treated water was normalized to the initial DOC concentration $\left(C_{o}\right)$. (A) Chloride concentration of $<2.6 \mathrm{mg} / \mathrm{L}$, (B) $36 \mathrm{mg} / \mathrm{L}$, (C) $71 \mathrm{mg} / \mathrm{L}$, respectively. (D) Box plots of bromide removal with different chloride concentrations. Number of observations $(n)$ of each box plot is 24 samples.

If ion exchange is the main adsorption mechanism for charged DOM, as reported by Boyer and Singer (2008) and Bond et al. (2010), then increasing the chloride concentrations should have a significant negative effect on their adsorption processes (Lin et al. 2011; Hu et al. 2013). Thus, the effects of increasing chloride concentrations from $<2.6 \mathrm{mg} / \mathrm{L}$ to $71 \mathrm{mg} / \mathrm{L}$ on the removal rates of tannic acid and glutamic acid were investigated. It was found that significantly increasing the chloride concentration reduced the removal rates of glutamic acid from $79 \%$ to $21 \%$ by the MIEX $^{\circledR}$ resin, but only a slight reduction in the removal rates of tannic acid from $92 \%$ to $83 \%$ was observed. These different results suggest that although ion exchange is the main mechanism for glutamic acid removal by MIEX $^{\circledR}$ resin, it is not the main mechanism for tannic acid adsorption. The synergistic combination of ion exchange and other mechanisms, such as hydrophobic interactions and hydrogen bonding, may control 
tannic acid removal by MIEX $^{\circledR}$ resin, which is similar to the previously reported adsorption mechanisms of tannic adsorption on carbon nanotubes (Lin and Xing 2008) and on surfactant-modified zeolite (Lin et al. 2011).

The bromide removal rates by the MIEX $^{\circledR}$ resin from the raw water ranged from $89 \%$ to $92 \%$ (Table 2 ), although the anion exchange capacity $(\sim 5 \mathrm{meq} / \mathrm{L})$ of the MIEX ${ }^{\circledR}$ resin was sufficiently high for the adsorption of all of the bromide ions in raw water. The bromide removal by the MIEX ${ }^{\circledR}$ resin could be lowered by competitive adsorption of DOM, chloride, sulfate, nitrate and other anions due to a reduction of adsorption sites (Hsu and Singer 2010; Phetrak et al. 2014); however, competitive adsorption of anions appeared unlikely because of the low concentration of anions (except for chloride) present in the raw waters (Table 1). Thus, it was estimated that the high chloride concentration was the only influencing factor on the bromide removal by the $\mathrm{MIEX}^{\circledR}$ resin. Hence, the effect of chloride concentration on bromide removal was investigated using synthetic waters. The mean bromide removal rates ( $n=24$ ) were reduced from $>98 \%$ to $93 \%$ and $88 \%$ by increasing chloride concentrations from $<2.6 \mathrm{mg} / \mathrm{L}$ to $36 \mathrm{mg} / \mathrm{L}$ and $71 \mathrm{mg} / \mathrm{L}$, respectively (Fig. 3D). Hsu and Singer (2010) also reported that an increase in the chloride concentration from $19 \mathrm{mg} / \mathrm{L}$ to $31 \mathrm{mg} / \mathrm{L}$ decreased the amount of bromide removed by approximately $10 \mu \mathrm{g} / \mathrm{L}$. The mean bromide removal rate of $88 \%$ in synthetic waters with a chloride concentration of $71 \mathrm{mg} / \mathrm{L}$ was consistent with the bromide removal rates of the raw waters containing $64-75 \mathrm{mg} / \mathrm{L}$ of chloride. These results suggested that high chloride concentrations in the raw waters hindered the release of chloride from the exchange sites of the MIEX $^{\circledR}$ resin, thereby reducing bromide adsorption.

Our results indicated that a high chloride concentration in the reservoir waters in sub-tropical islands is an important factor that influences the removal rates of not only bromide but also charged DOM, such as HPI acid, by the MIEX ${ }^{\circledR}$ resin. Furthermore, DOM characteristics, such as aromaticity and charge state, are also important factors that influence DOM removal by the AER (Li and Sengupta, 1998).

\subsubsection{Molecular weight distribution and F-EEM characterization of DOM}

To better understand the DOM removal characteristics by the MIEX ${ }^{\circledR}$ resin, raw waters and MIEX $^{\circledR}$-treated waters were further analyzed by HPSEC and F-EEM. Figure 4 shows the HPSEC chromatogram of the raw waters and the MIEX ${ }^{\circledR}$-treated waters. The DOM in the raw waters had AMW values smaller than $4 \mathrm{kDa}$, showing five peaks at 2.3, 2.0, 1.8, 1.4 , and $0.7 \mathrm{kDa}$. DOM with a large AMW of $>1 \mathrm{kDa}$, representing AMW of HPO and HPI acids, was preferentially removed from the raw waters by the IIEX $^{\circledR}$ resin, whereas DOM 
with a low AMW (ca. $0.7 \mathrm{kDa}$, equivalent to the AMW of HPI non-acid) (Fig. S1), remained in MIEX $^{\circledR}$-treated waters. Our results were in agreement with those found elsewhere in the literature (Drikas et al. 2011; Humbert et al. 2005; Phetrak et al. 2012). DOM with larger AMW tends to be more aromatic and has a higher charge density than the smaller AMW compounds (Shuang et al. 2014), whereas HPI non-acid compounds obtained from the resin fractionation technique had a lower AMW and charge density (Leenheer and Croué 2003).

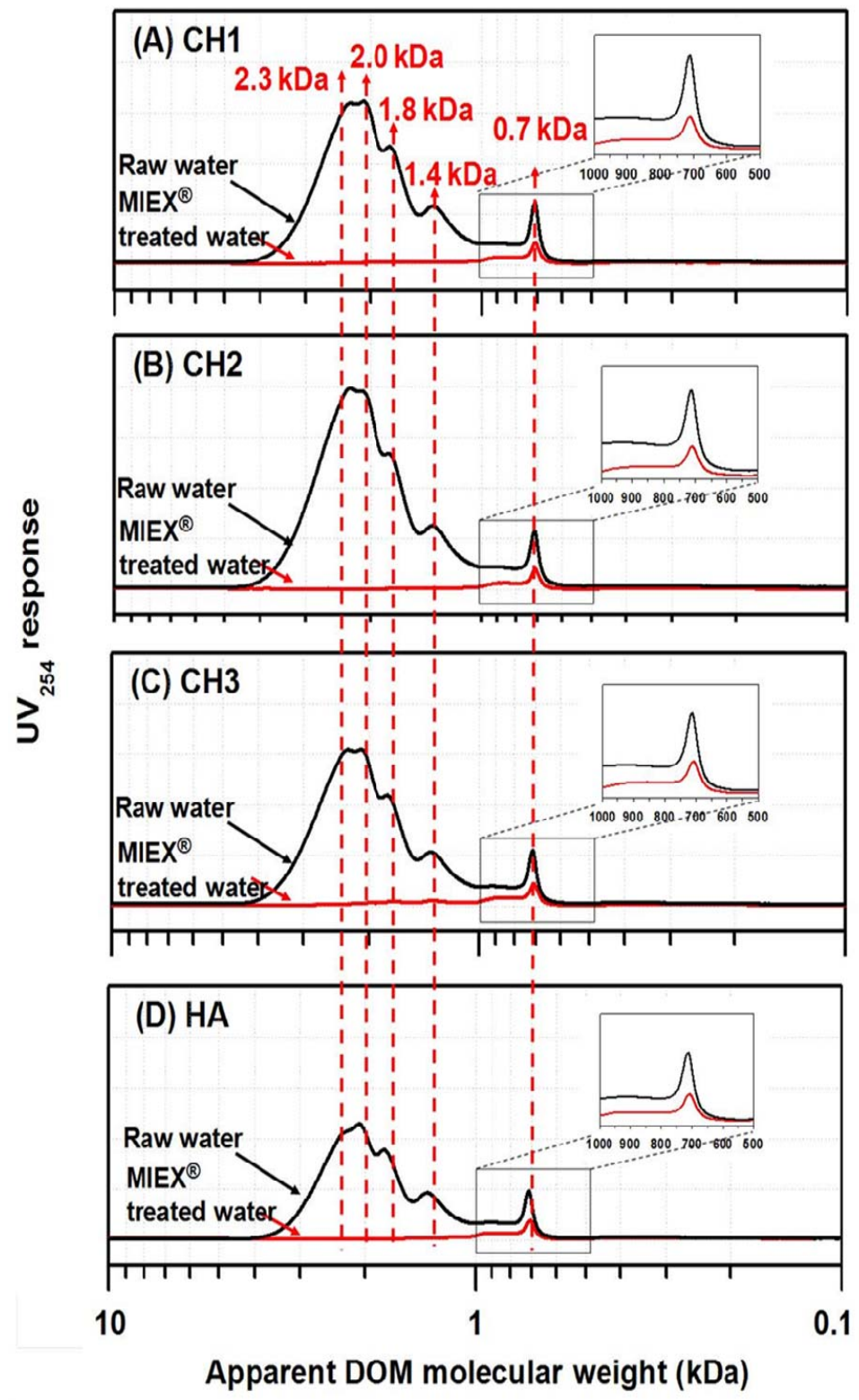

Fig. 4. Apparent DOM molecular weight distribution before and after MIEX ${ }^{\circledR}$ treatment: (A) $\mathrm{CH} 1,(\mathrm{~B}) \mathrm{CH} 2$, (C) $\mathrm{CH} 3$ and (D) HA. MIEX ${ }^{\circledR}$ dose of $8 \mathrm{~g} / \mathrm{L}$, contact time of $30 \mathrm{~min}$. 
Based on the SUVA 254 , HPSEC chromatogram and surrogate DOM adsorption results, it was estimated that the charged DOM was preferentially adsorbed by the MIEX ${ }^{\circledR}$ resin primarily through an ion exchange mechanism. However, physical DOM adsorption mechanisms, such as hydrophobic, polar interactions and hydrogen bonding, could also be involved in the adsorption of high MW aromatic DOM, such as the HPO acid fraction, which is represented by tannic acid (Lin and Xing 2008; Lin et al. 2011). These findings are in agreement with the removal rates of each DOM fraction by the MIEX $^{\circledR}$ resin as measured by the F-EEM (Figs. 5 and S2). F-EEM volumes (accumulated fluorescence intensities) of the individual regions in the F-EEM spectra of raw water and MIEX $^{\circledR}$-treated waters were computed using the fluorescence regional integration proposed by Chen et al. (2003). The F-EEM showed the reduction of the DOM fractions as follows: aromatic proteins by $39 \%-50 \%$ and SMP-like compounds by 59\%-64\%. SPMs are represented by protein-like compounds, which are amphoteric (Leenheer and Croué 2003), with a net negative charge at $\mathrm{pH}$ values above their isoelectric point. Thus, they could be removed by ion exchange, as reported by Cornelissen et al. (2008). In addition, higher removal rates of fluorescent humic acid-like (89\%-92\%) and fulvic acid-like compounds (86\%-90\%) were achieved by the MIEX $^{\circledR}$ resin. Because the molecular structure of humic acid-like and fulvic acid-like compounds is similar to that of tannic acid, we anticipate that the removal of these compounds was governed not only by ion exchange but also by physical adsorption.

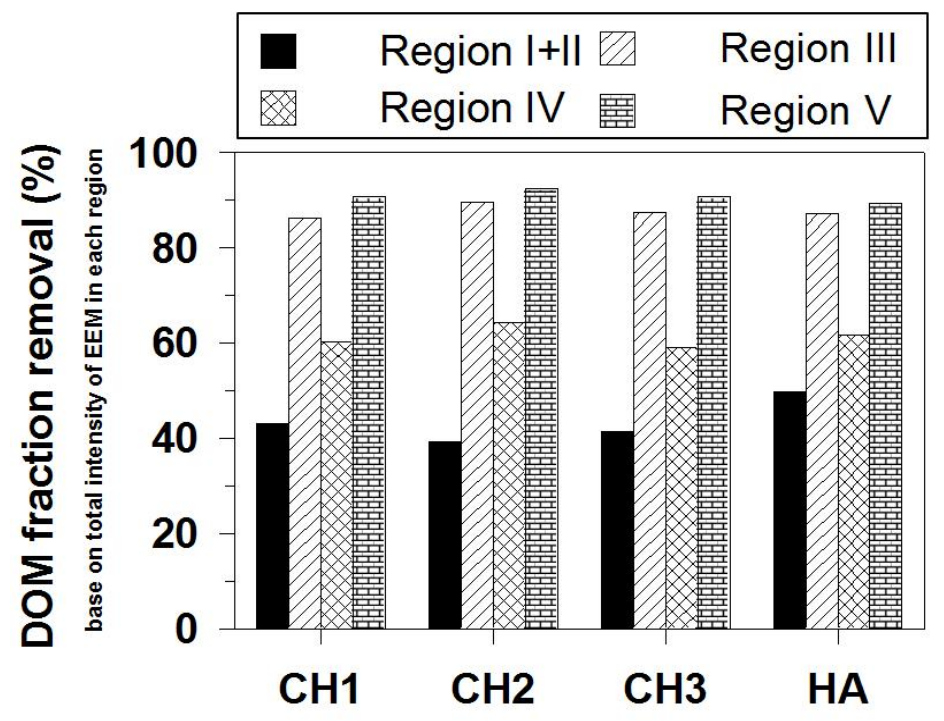

Fig. 5. Reductions in total fluorescence intensity of each fluorescent region. MIEX ${ }^{\circledR}$ resin dose 8 g/L, contact time $30 \mathrm{~min}$. Regions I+II (Ex: 220-270/Em: 280-380): Aromatic 
proteins (tyrosine and tryptophan-like compounds). Region III (Ex: 220-270/Em: 380-550): Fulvic acid-like compounds. Region IV (Ex: 270-440/Em: 280-380): SMP-like compounds. Region V (Ex: 270-440/Em: 380-550): Humic acid-like compounds.

\subsection{Reduction of trihalomethane formation potential (THMFP)}

Figure 6 shows the concentration of THMFP and the specific THMFP (THMFP/DOC) of different DOM fractions obtained from raw water. The HPO acid fraction contributed to the highest THMFP of $114-162 \mu \mathrm{g} / \mathrm{L}$ due to its predominance in the raw waters and the fact that aromatic structures constitute the primary sites attacked by chlorine (Reckhow et al. 1990). The HPI acid fraction had the highest specific THMFP of 41-55 $\mu \mathrm{g} / \mathrm{mg}-\mathrm{C}$, followed by HPO acid at $22-37 \mu \mathrm{g} / \mathrm{mg}-\mathrm{C}$ and HPI non-acid at 4-16 $\mu \mathrm{g} / \mathrm{mg}-\mathrm{C}$. These results indicated that HPO and HPI acids were the important DOM fractions contributing to THM formation in raw waters because they provided the largest THMFP and the highest specific THMFP, respectively. In contrast, the HPI non-acid fraction had the lowest amount of THMFP and the smallest specific THMFP among the three DOM fractions; thus, this fraction may not be an important fraction of the THMFP.
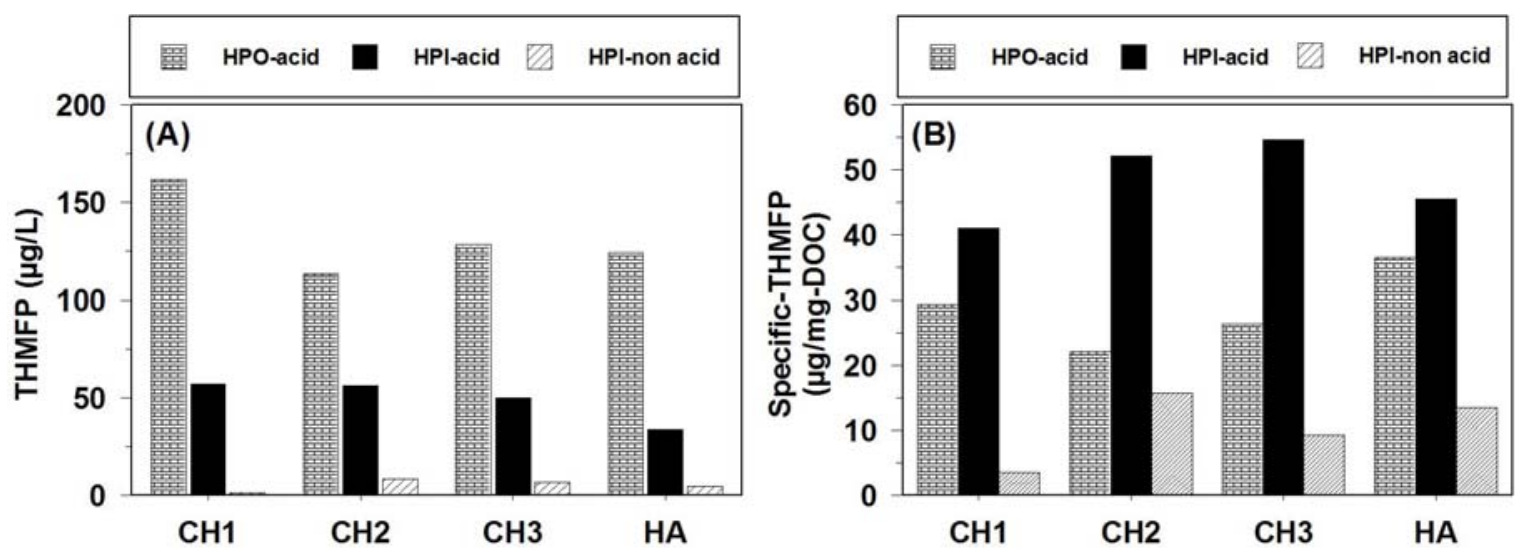

Fig. 6. (A) THMFP of different DOM fractions in raw water, and (B) specific THMFP of different DOM fractions in raw water.

Brominated THMs have much higher health risks than their chlorinated analogs (Richardson et al. 1999). Thus, the bromine incorporation factor (BIF), showing the amount of brominated THM (BIF $\left.{ }_{\mathrm{THM}}\right)$ formation, was calculated for all of the DOM fractions of the chlorinated samples, as described by Kaplan Bekaroglu et al. (2010), to investigate the role of bromine in THM formation. The results (Table S3) revealed that bromine was the most 
reactive with the HPI acid, followed by HPI non-acid and HPO acid. Similar results have been reported in other studies (Hua and Reckhow 2007; Kitis et al. 2002). These results suggest that water treatment plant operators should attempt to eliminate HPO and HPI acids to control THM formation because HPO acid contributed to the THMFP by the largest fraction, while HPI acid showed the highest specific THMFP and was the most reactive with bromide in raw waters to form brominated THMs. Although the HPI non-acid fraction has been reported as difficult to remove using conventional treatment processes (Kitis et al. 2002), this fraction does not appear to pose serious risks concerning THM formation by chlorination.
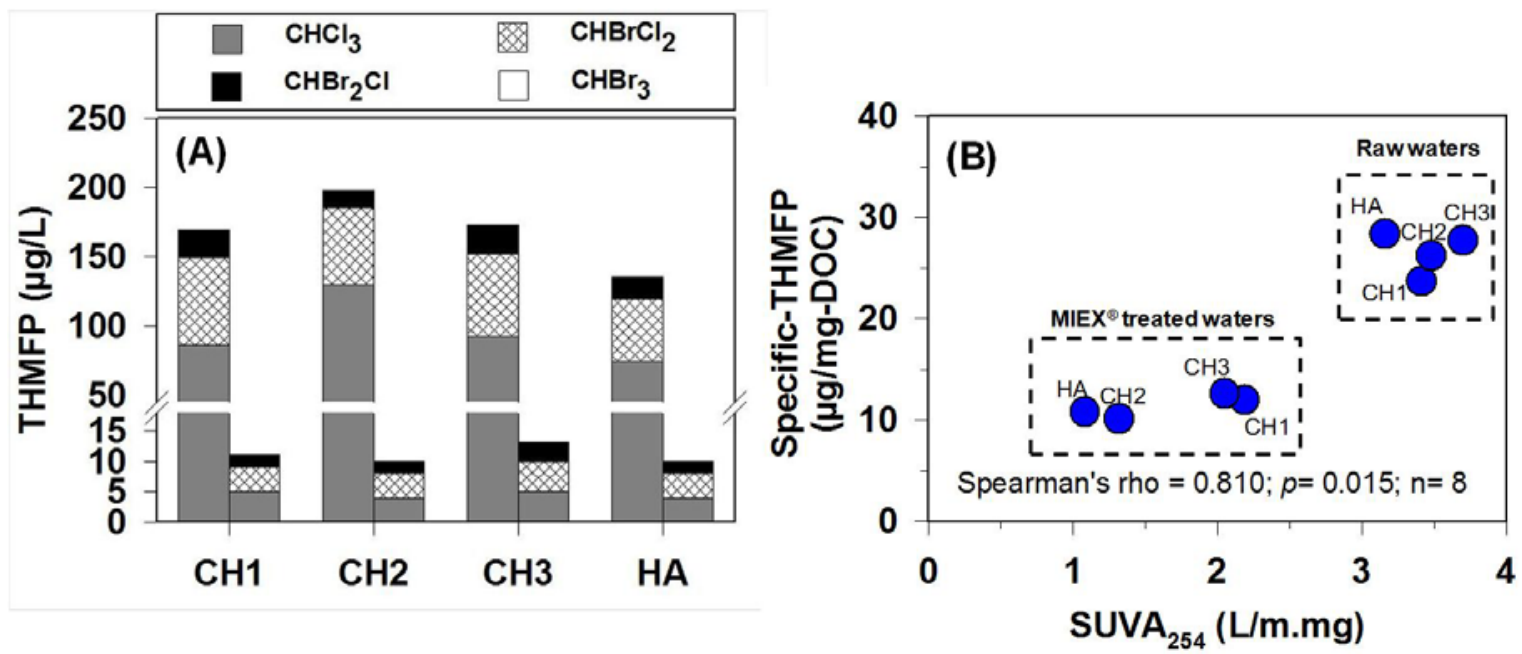

Fig. 7. (A) THMFP concentration before and after MIEX ${ }^{\circledR}$ treatment and (B) Relationship between SUVA $_{254}$ and specific-THMFP before and after MIEX ${ }^{\circledR}$ treatment. MIEX ${ }^{\circledR}$ dose of 8 $\mathrm{g} / \mathrm{L}$, contact time of $30 \mathrm{~min}$.

Figure 7A shows the concentration of THM species before and after the MIEX ${ }^{\circledR}$ treatment. The highest concentration of THM species detected in the raw waters was found to be $\mathrm{CHCl}_{3}(74-130 \mu \mathrm{g} / \mathrm{L})$, followed by $\mathrm{CHBrCl}_{2}(45-63 \mu \mathrm{g} / \mathrm{L})$ and $\mathrm{CHBr}_{2} \mathrm{Cl}(13-21 \mu \mathrm{g} / \mathrm{L})$. However, $\mathrm{CHBr}_{3}$ was not detected by chlorination of the raw waters, as reported by Tubić et al. (2013). Brominated THMs in the raw water represented $34 \%-49 \%$ of the total-THMFP (the sum of $\mathrm{CHBrCl}_{2}, \mathrm{CHBr}_{2} \mathrm{Cl}$ and $\mathrm{CHBr}_{3}$ ). After the $\mathrm{MIEX}^{\circledR}$ treatment, the brominated and total THMFPs were significantly reduced by $90 \%-93 \%$ and $92 \%-95 \%$, respectively, because a substantial amount of reactive DOM fractions and bromide were concurrently removed. 
Figure 7B shows the correlation between $\mathrm{SUVA}_{254}$ and specific THMFP before and after the MIEX $^{\circledR}$ treatment. Although a narrow range of SUVA $_{254}$ between 1.09 and 3.70 L/m.mg was observed, a positive correlation (Spearman's rho $=0.810 ; p$ value $=0.015$ ) between $\mathrm{SUVA}_{254}$ and specific-THMFP was found in this study, which was consistent with the results of Kitis et al. (2002). In contrast, a poor correlation between $\mathrm{SUVA}_{254}$ and specific THMFP was observed in low SUVA 254 waters (Ates et al. 2007). However, our results and others from the literature suggest that the $\mathrm{SUVA}_{254}$ value is a useful indicator of THMFP in high SUVA $_{254}$ waters, such as those found in reservoir waters from sub-tropical islands containing allochthonous DOM.

\section{4.\# CONCLUSIONS}

The conclusions obtained in this study are as follows:

- The major fraction of DOM in reservoir waters in the Ogasawara Islands was the HPO acid fraction ( $75 \%$ of the total DOM), which had the highest contribution to the THMFP of 114 to $162 \mu \mathrm{g} / \mathrm{L}$, whereas the HPI acid fraction of DOM showed the highest specific THMFP and reactivity with bromide to form brominated-THMFP after chlorination.

- The use of surrogate DOM compounds representing each DOM fraction combined with varying the chloride concentration was found to be an effective approach to elucidate the removal mechanisms of the DOM fractions by the MIEX $^{\circledR}$ resin. The removal rates of glutamic acid (HPI acid surrogate) were significantly influenced by the chloride concentration, while the removal rates of tannic acid (HPO acid surrogate) were only moderately influenced by the elevated chloride concentrations. These results indicated that HPI acid (glutamic acid) was removed by the $\mathrm{MIEX}^{\circledR}$ via the ion exchange mechanism, whereas a combination of ion exchange and physical adsorption contributed to the removal of HPO acid (tannic acid) by the MIEX $^{\circledR}$ resin.

- The DOM in raw waters had an AMW below $4 \mathrm{kDa}$, of which DOM greater than $1 \mathrm{kDa}$, representing HPO acid and HPI acid, was preferentially removed by the MIEX $^{\circledR}$ resin. However, DOM with an AMW smaller than $1 \mathrm{kDa}$, representing HPI non-acid, was not effectively removed by the $\mathrm{MIEX}^{\circledR}$ resin. These differences in the removal rates of the DOM fractions and their surrogate DOM were also confirmed by the results of the F-EEM measurements. 


\section{5.\# ACKNOWLEDGMENTS}

The author would like to thank Maezawa Industries, Inc. for their assistance in the ion exchange experiments with the MIEX $^{\circledR}$ resin used for this study. This study was supported by the Environment Research and Technology Development Fund (S-8) of the Ministry of the Environment, Japan, Grant-in-Aid for Scientific Research (\#22404012) by JSPS and the CREST Project Fund by JST.

\section{6.\# REFERENCES}

Ates, N., Kitis, M., and Yetis, U., 2007. Formation of chlorination by-products in waters with low SUVA-correlations with SUVA and differential UV spectroscopy. Water Research, 41(18), 4139-4148.

Bond, T., Goslan, E. H., Parsons, S. A., and Jefferson, B., 2010. Disinfection by-product formation of natural organic matter surrogates and treatment by coagulation, MIEX ${ }^{\circledR}$ and nanofiltration. Water Research, 44(5), 1645-1653.

Boyer, T.H. and Singer, P.C., 2008. Stoichiometry of removal of natural organic matter by ion exchange. Environmental Science \& Technology 42(2), 608-613.

Chen, W., Westerhoff, P., Leenheer, J. A., and Booksh, K., 2003. Fluorescence excitation-emission matrix regional integration to quantify spectra for dissolved organic matter. Environmental Science \& Technology, 37(24), 5701-5710.

Chiang, P. C., Chang, E. E., Chang, P. C., and Huang, C. P., 2009. Effects of pre-ozonation on the removal of THM precursors by coagulation. Science of the Total Environment, 407(21), 5735-5742.

Chu, W.H., Gao, N.Y., Deng, Y. and Krasner, S.W. 2010. Precursors of dichloroacetamide, an emerging nitrogenous DBP formed during chlorination or chloramination. Environmental Science \& Technology, 44(10), 3908-3912.

Chu, W., Li, D., Gao, N., Templeton, M.R., Tan, C. and Gao, Y., 2015. The control of emerging haloacetamide DBP precursors with UV/persulfate treatment. Water Research, 72, 340-348.

Cornelissen, E. R., Moreau, N., Siegers, W. G., Abrahamse, A. J., Rietveld, L. C., Grefte, A., Dignum, M., Amy, G., and Wessels, L. P., 2008. Selection of anionic exchange resins for removal of natural organic matter (NOM) fractions. Water Research, 42, 413-423.

Croué, J.P., Violleau, D., Bodaire, C. and Legube, B., 1999. Removal of hydrophobic and hydrophilic constituents by anion exchange resin. Water Science and Technology 40(9), 207-214. 
Drikas, M., Dixon, M., and Morran, J., 2011. Long term case study of MIEX pre-treatment in drinking water; understanding NOM removal. Water Research, 45(4), 1539-1548.

Fabris, R., Chow, C. W., Drikas, M., and Eikebrokk, B., 2008. Comparison of NOM character in selected Australian and Norwegian drinking waters. Water Research, 42(15), 4188-4196.

Freeman, C., Ostle, N., and Kang, H., 2001. An enzymic 'latch' on a global carbon store. Nature, 409(6817), 149-149.

Gan, X., Karanfil, T., Kaplan Bekaroglu, S.S. and Shan, J., 2013. The control of N-DBP and C-DBP precursors with MIEX ${ }^{\circledR}$. Water Research 47(3), 1344-1352.

Gough, R., Holliman, P. J., Willis, N., and Freeman, C., 2014. Dissolved organic carbon and trihalomethane precursor removal at a UK upland water treatment works. Science of the Total Environment, 468, 228-239.

Hsu, S., and Singer, P. C., 2010. Removal of bromide and natural organic matter by anion exchange. Water Research, 44(7), 2133-2140.

Hu, Y., Guo, T., Ye, X., Li, Q., Guo, M., Liu, H., and Wu, Z., 2013. Dye adsorption by resins: Effect of ionic strength on hydrophobic and electrostatic interactions. Chemical Engineering Journal, 228, 392-397.

Hua, G., and Reckhow, D. A., 2007. Characterization of disinfection byproduct precursors based on hydrophobicity and molecular size. Environmental Science \& Technology, 41(9), 3309-3315.

Humbert, H., Gallard, H., Suty, H., and Croué, J. P., 2005. Performance of selected anion exchange resins for the treatment of a high DOC content surface water. Water Research, 39(9), 1699-1708.

Hussain, S., van Leeuwen, J., Chow, C., Beecham, S., Kamruzzaman, M., Wang, D., Drikas, M., and Aryal, R., 2013. Removal of organic contaminants from river and reservoir waters by three different aluminum-based metal salts: Coagulation adsorption and kinetics studies. Chemical Engineering Journal, 225, 394-405.

Imai, A., Fukushima, T., Matsushige, K., Kim, Y. H., and Choi, K., 2002. Characterization of dissolved organic matter in effluents from wastewater treatment plants. Water Research, 36(4), 859-870.

Imai, A., Matsushige, K. and Nagai, T., 2003. Trihalomethane formation potential of dissolved organic matter in a shallow eutrophic lake. Water Research, 37(17), 4284-4294.

Japan Water Works Association, (2001). Standard Methods for the Examination of Water (in 
Kaplan Bekaroglu, S. S., Yigit, N. O., Karanfil, T., and Kitis, M., 2010. The adsorptive removal of disinfection by-product precursors in a high-SUVA water using iron oxide-coated pumice and volcanic slag particles. Journal of Hazardous Materials, 183(1-3), 389-394.

Kim, H. C. and Yu, M. J., 2005. Characterization of natural organic matter in conventional water treatment processes for selection of treatment processes focused on DBPs control. Water Research 39(19), 4779-4789.

Kitis, M., Karanfil, T., Wigton, A., and Kilduff, J. E., 2002. Probing reactivity of dissolved organic matter for disinfection by-product formation using XAD-8 resin adsorption and ultrafiltration fractionation. Water Research, 36(15), 3834-3848.

Kristiana, I., Joll, C. and Heitz, A. (2011) Powdered activated carbon coupled with enhanced coagulation for natural organic matter removal and disinfection by-product control: Application in a Western Australian water treatment plant. Chemosphere 83(5), 661-667.

Lamsal, R., Montreuil, K. R., Kent, F. C., Walsh, M. E., and Gagnon, G. A., 2012. Characterization and removal of natural organic matter by an integrated membrane system. Desalination, 303, 12-16.

Leenheer, J. A., and Croué, J. P., 2003. Characterizing aquatic dissolved organic matter. Environmental Science \& Technology, 37(1), 18A-26A.

Li, P., and Sengupta, A. K., 1998. Genesis of selectivity and reversibility for sorption of synthetic aromatic anions onto polymeric sorbents. Environmental Science \& Technology, 32(23), 3756-3766.

Lin, D., and Xing, B., 2008. Tannic acid adsorption and its role for stabilizing carbon nanotube suspensions. Environmental Science \& Technology, 42(16), 5917-5923.

Lin, J., Zhan, Y., Zhu, Z., and Xing, Y., 2011. Adsorption of tannic acid from aqueous solution onto surfactant-modified zeolite. Journal of Hazardous Materials, 193, $102-111$.

Liu, X., Chen, Z., Wang, L. and Shen, J., 2012. Effects of metal ions on THMs and HAAs formation during tannic acid chlorination. Chemical Engineering Journal, 211-212, 179-185.

Lohwacharin, J., Oguma, K., and Takizawa, S., 2010. Use of carbon black nanoparticles to mitigate membrane fouling in ultrafiltration of river water. Separation and Purification Technology, 72(1), 61-69.

Lohwacharin, J., and Takizawa, S., 2009. Effects of nanoparticles on the ultrafiltration of 
surface water. Journal of Membrane Science, 326(2), 354-362.

Magazinovic, R.S., Nicholson, B.C., Davey, D.E., Mulcahy, D.E. and Davey, D.E., 2004. Bromide levels in natural waters: its relationship to levels of both chloride and total dissolved solids and the implications for water treatment. Chemosphere 57, 329-335.

McKnight, D. M., Boyer, E. W., Westerhogg, P. K., Doran, P. T., Kulbe, T., and Andersen, D. T., 2001. Spectrofluorometric characterization of dissolved organic matter for indication of precursor organic material and aromaticity. Limnology and Oceanography, 46(1), 38-48.

Norwood, D.L., Christman, R.F., and Hatcher, P.G., 1987 Structural characterization of aquatic humic material. 2. Phenolic content and its relationship to chlorination mechanism in an isolated aquatic fulvic acid. Environmental Science \& Technology 21(8), 791-798.

Oćwieja, M., Adamczyk, Z. and Morga, M., 2015. Adsorption of tannic acid on polyelectrolyte monolayers determined in situ by streaming potential measurements. Journal of Colloid and Interface Science 438, 249-258.

Phetrak, A., Lohwacharin, J., Sakai, H., Murakami, M., Oguma, K., and Takizawa, S., 2014. Simultaneous removal of dissolved organic matter and bromide from drinking water source by anion exchange resins for controlling disinfection by-products. Journal of Environmental Sciences, 26(6), 1294-1300.

Phetrak, A., Lohwacharin, J., Watanabe, N., Murakami, M., Sakai, H., Oguma, K., and Takizawa, S., 2012. Competitive removal of dissolved organic matter (DOM) and inorganic anions by anion exchange resins (AERs). Water Science and Technology: Water Supply, 12(5), 630-636.

Rautio, M., Mariash, H., and Forsström, L., 2011. Seasonal shifts between autochthonous and allochthonous carbon contributions to zooplankton diets in a subarctic lake. Limnology and Oceanography, 56(4), 1513-1524.

Reckhow, D. A., Singer, P. C., and Malcolm, R. L., 1990. Chlorination of humic materials: byproduct formation and chemical interpretations. Environmental Science \& Technology, 24(11), 1655-1664.

Richardson, S. D., Thruston, A. D., Caughran, T. V., Chen, P. H., Collette, T. W., Floyd, T. L., Schenck, K. M., Lykins, B. W., Sun, G.-.R., and Majetich, G., 1999. Identification of new drinking water disinfection byproducts formed in the presence of bromide. Environmental Science \& Technology, 33(19), 3378-3383.

Sellner, K.G. and Nealley, E.W., 1997. Diel fluctuations in dissolved free amino acids and 
monosaccharides in Chesapeake Bay dinoflagellate blooms. Marine Chemistry 56, 193-200.

Sharp, E., Banks, J., Billica, J., Gertig, K., Henderson, R., Parsons, S., Wilson, D., and Jefferson, B., 2005. Application of zeta potential measurements for coagulation control: pilot-plant experiences from UK and US waters with elevated organics. Water Science and Technology: Water Supply, 5(5), 49-56.

Shuang, C., Wang, M., Li, P., Li, A., Zhou, Q., Pan, F., and Zhou, W., 2014. Adsorption of humic acid fractions with different molecular weight by magnetic polyacrylic anion exchange resin. Journal of Soils and Sediments, 14(2), 312-319.

Thurman, E.M., 1985. Organic Geochemistry of Natural Waters. Nijhoff/Junk Publishers, Dordrecht, The Netherlands.

Tochimoto, H., Kosugi, Y., Konishi, H., Inomata, A., Muto, C., Kurita, M., Yaguchi, K., Chiba, H., and Ohtsuka, H., 2010. Quality of raw water for drinking-water supply on the Ogasawara Islands focusing on formation potentials of disinfection by-products. Journal of Japan Society on Water Environment, 33(11), 181-191 (In Japanese).

Tubić, A., Agbaba, J., Dalmacija, B., Molnar, J., Maletić, S., Watson, M., and Perović, S. U., 2013. Insight into changes during coagulation in NOM reactivity for trihalomethanes and haloacetic acids formation. Journal of Environmental Management, 118, 153-160.

Wang, L.Y., Wu, F.C., Zhang, R.Y., Li, W., and Liao, H.Q., 2009. Characterization of dissolved organic matter fractions from Lake Hongfeng, Southwestern China Plateau. Journal of Environmental Sciences, 21(5), 581-588.

Xu, B., Gao, N. Y., Sun, X. F., Xia, S. J., Simonnot, M. O., Causserand, C., Rui, M., and Wu, H. H., 2007. Characteristics of organic material in Huangpu River and treatability with the $\mathrm{O}_{3}$-BAC process. Separation and Purification Technology, 57(2), 348-355.

Xu, Z., Jiao, R., Liu, H., Wang, D., Chow, C.W., and Drikas, M., 2013. Hybrid treatment process of using MIEX and high performance composite coagulant for DOM and bromide removal. Journal of Environmental Engineering, 139(1), 79-85.

Yang, J. S., Yuan, D. X., and Weng, T. P., 2010. Pilot study of drinking water treatment with GAC, O3/BAC and membrane processes in Kinmen Island, Taiwan. Desalination, 263(1-3), 271-278.

Yang, Y., Takizawa, S., Sakai, H., Murakami, M., and Watanabe, N., 2012. Removal of organic matter and phosphate using ferrihydrite for reduction of microbial regrowth potential. Water Science \& Technology, 66(6), 1348-1353. 